\title{
Alcohol Consumption and Binge Drinking During Pregnancy Among Adults Aged 18-49 Years — United States, 2018-2020
}

\author{
Lucas K. Gosdin, $\mathrm{PhD}^{1,2}$; Nicholas P. Deputy, $\mathrm{PhD}^{1}$; Shin Y. Kim, MPH${ }^{1}$; Elizabeth P. Dang, MPH${ }^{1}$; Clark H. Denny, PhD ${ }^{1}$
}

There is no known safe amount of alcohol consumption during pregnancy; drinking alcohol during pregnancy can cause fetal alcohol spectrum disorders and might increase the risk for miscarriage and stillbirth (1). The prevalence of drinking among pregnant women increased slightly during 2011-2018; however, more recent estimates are not yet reported (2). CDC estimated the prevalence of self-reported current drinking (at least one alcoholic drink in the past 30 days) and binge drinking (consuming four or more drinks on at least one occasion in the past 30 days) among pregnant adults aged 18-49 years, overall and by selected characteristics, using 2018-2020 Behavioral Risk Factor Surveillance System (BRFSS) data. During 2018-2020, 13.5\% of pregnant adults reported current drinking and 5.2\% reported binge drinking: both measures were 2 percentage points higher than during 2015-2017. Pregnant adults with frequent mental distress were 2.3 and 3.4 times as likely to report current and binge drinking, respectively, compared with those without frequent mental distress. In addition, pregnant adults without a usual health care provider were 1.7 times as likely to report current drinking as were those with a current provider. Alcohol consumption during pregnancy continues to be a serious problem. Integration of mental health services into clinical care and improving access to care might help address alcohol consumption and mental distress during pregnancy to prevent associated adverse outcomes (3).

BRFSS is an annual, state-based, random-digit-dialed telephone survey of health-related behaviors representative of noninstitutionalized adults aged $\geq 18$ years in the United States and participating territories. CDC analyzed 2018-2020 BRFSS self-reported data from 6,327 pregnant adults aged $18-49$ years from all 50 U.S. states* and the District of Columbia. The analysis included all pregnant respondents irrespective of gender identity. In 2018, 2019, and 2020, median BRFSS response rates were $49.9 \%$ (range $=38.8 \%-67.2 \%$ ), $49.4 \%$ $(37.3 \%-73.1 \%)$, and $47.6 \%(34.5 \%-67.2 \%)$, respectively. ${ }^{\dagger}$

Persons who reported their sex at birth as female were asked if they were currently pregnant. Current drinking ${ }^{\S}$ and

\footnotetext{
* New Jersey did not collect sufficient data to meet the minimum requirements for inclusion in 2019 BRFSS public use data set.

${ }^{\dagger}$ Response rates were calculated using standards set by the American Association for Public Opinion Research. https://www.aapor.org/Standards-Ethics/ Standard-Definitions-(1).aspx

$\S$ Current drinking was defined as a response of "one or more" to the question, "During the past 30 days, how many days per week or per month did you have at least one drink of any alcoholic beverage such as beer, wine, a malt beverage or liquor?" https://www.cdc.gov/brfss/questionnaires/pdf-ques/2020-BRFSSQuestionnaire-508.pdf
}

binge drinking were defined based on 2020-2025 Dietary Guidelines for Americans.** Sociodemographic and health characteristics examined in this analysis included age, race/ ethnicity, education, employment status, marital status, having a usual health care provider, ${ }^{\dagger \dagger}$ and experiencing frequent mental distress. $\$ \$$

Among pregnant adults, CDC estimated the prevalence and 95\% CIs for current and binge drinking, overall and by sociodemographic and health characteristics and U.S. Department of Health and Human Services (HHS) region. 99 Multivariable regression was used to estimate adjusted prevalence ratios (aPRs) and $95 \%$ CIs to identify factors associated with current and binge drinking. To understand potential differences associated with the COVID-19 pandemic, the overall prevalence estimates were examined by year. Differences by year and HHS region were examined using Rao-Scott chi-square tests. Data were weighted to represent state-level population estimates and aggregated to represent regional and national estimates. P-values $<0.05$ and $95 \%$ CIs of aPRs that excluded 1.0 were considered statistically significant. SAS statistical software (version 9.4; SAS Institute) SURVEY procedures were used to account for complex sampling. This activity was reviewed by CDC and was conducted consistent with applicable federal law and CDC policy.**

Among pregnant adults, $13.5 \%$ reported current drinking and $5.2 \%$ reported binge drinking $(38.5 \%$ of current drinkers) (Table). The prevalence of current drinking did not differ significantly by year: $11.8 \%(95 \% \mathrm{CI}=9.6-14.1)$ in 2018 , $14.6 \%(11.2 \%-17.9 \%)$ in 2019 , and $14.3 \%(10.5 \%-18.1 \%)$ in $2020(\mathrm{p}=0.40)$. The prevalence of binge drinking also did

\footnotetext{
I Binge drinking was defined as a response of "one or more" to the question, "Considering all types of alcoholic beverages, how many times during the past 30 days did you have four or more drinks on an occasion?"

** https://www.dietaryguidelines.gov/sites/default/files/2020-12/Dietary_ Guidelines_for_Americans_2020-2025.pdf

${ }^{\dagger}$ Having a usual health care provider was ascertained by response to the question, "Do you have one person you think of as your personal doctor or health care provider?" Participants who answered "no" were asked, "Is there more than one, or is there no person who you think of as your personal doctor or health care provider?" Responses were dichotomized into one or more (yes) or none (no).

$\$ \$$ Frequent mental distress was defined as a response of $\geq 14$ to the question, "Now thinking about your mental health, which includes stress, depression, and problems with emotions, for how many days during the past 30 days was your mental health not good?" https://www.cdc.gov/hrqol/pdfs/mhd.pdf

I9 Sample sizes permitted examination of current drinking only by HHS region. https://www.hhs.gov/about/agencies/iea/regional-offices/index.html

*** 45 C.F.R. part 46, 21 C.F.R. part 56; 42 U.S.C. Sect. 241 (d); 5 U.S.C. Sect. 552a; 44 U.S.C. Sect. 3501 et seq
} 
Morbidity and Mortality Weekly Report

TABLE. Estimated prevalence* and adjusted prevalence ratios of current drinking ${ }^{\dagger}$ and binge drinking ${ }^{\S}$ reported by pregnant adults aged 18-49 years $(\mathrm{N}=6,327)$, by selected characteristics - Behavioral Risk Factor Surveillance System, United States, 2018-2020

\begin{tabular}{|c|c|c|c|c|}
\hline \multirow[b]{2}{*}{ Characteristic } & \multicolumn{2}{|c|}{ Current drinking } & \multicolumn{2}{|c|}{ Binge drinking } \\
\hline & $\%(95 \% \mathrm{Cl})$ & $\mathrm{aPR}^{\text {nी }}(95 \% \mathrm{Cl})$ & $\%(95 \% \mathrm{Cl})$ & $\mathrm{aPR}^{\mathrm{fl}}(95 \% \mathrm{Cl})$ \\
\hline Overall & $13.5(11.7-15.4)$ & - & $5.2(3.6-6.7)$ & - \\
\hline $\begin{array}{l}\text { Age group, yrs } \\
18-24 \\
25-29 \\
30-34 \\
35-49\end{array}$ & $\begin{array}{r}16.8(12.3-21.4) \\
10.3(7.5-13.1) \\
11.1(7.5-14.6) \\
17.0(13.8-20.2)\end{array}$ & $\begin{array}{l}1.0(0.7-1.3) \\
0.6(0.5-0.8) \\
0.6(0.4-0.9) \\
\quad \text { Ref }\end{array}$ & $\begin{array}{c}8.5(4.6-12.4)^{* *} \\
N A^{+\dagger} \\
N A^{+\dagger} \\
4.4(2.8-6.1)\end{array}$ & $\begin{array}{l}1.4(0.8-2.6) \\
0.6(0.3-1.2) \\
1.1(0.5-2.3) \\
\quad \text { Ref }\end{array}$ \\
\hline $\begin{array}{l}\text { Race/Ethnicity } \\
\text { White, non-Hispanic } \\
\text { Black, non-Hispanic } \\
\text { Hispanic } \\
\text { Other, non-Hispanic }\end{array}$ & $\begin{array}{l}12.7(10.9-14.5) \\
15.0(8.1-21.8)^{* *} \\
12.5(8.0-17.1) \\
17.2(11.5-23.0)\end{array}$ & $\begin{array}{l}1.1(0.7-1.6) \\
1.1(0.6-2.0) \\
\text { Ref } \\
1.4(0.9-2.3)\end{array}$ & $\begin{array}{l}4.1(2.9-5.3) \\
N A^{+\dagger} \\
N A^{+\dagger} \\
N A^{+\dagger}\end{array}$ & $\begin{array}{c}1.0(0.5-2.2) \\
1.5(0.5-4.5) \\
\text { Ref } \\
1.6(0.6-4.1)\end{array}$ \\
\hline $\begin{array}{l}\text { Education } \\
\text { High school diploma or less } \\
\text { Some college } \\
\text { College degree }\end{array}$ & $\begin{array}{r}10.2(7.3-13.0) \\
15.9(11.6-20.2) \\
15.7(13.2-18.1)\end{array}$ & $\begin{array}{c}\text { Ref } \\
1.8(1.2-2.5) \\
2.2(1.5-3.1)\end{array}$ & $\begin{array}{c}4.9(2.5-7.3)^{* *} \\
7.5(3.5-11.5)^{* *} \\
3.5(2.4-4.5)\end{array}$ & $\begin{array}{c}\text { Ref } \\
1.8(1.0-3.5) \\
1.2(0.6-2.3)\end{array}$ \\
\hline $\begin{array}{l}\text { Employment status } \\
\text { Employed } \\
\text { Not employed }\end{array}$ & $\begin{array}{r}15.6(13.1-18.2) \\
10.7(8.0-13.3)\end{array}$ & $\begin{array}{c}1.5(1.1-2.1) \\
\text { Ref }\end{array}$ & $\begin{array}{l}6.1(3.9-8.4) \\
3.9(1.9-5.8)^{* *}\end{array}$ & $\begin{array}{c}2.1(1.1-4.0) \\
\text { Ref }\end{array}$ \\
\hline $\begin{array}{l}\text { Marital status } \\
\text { Married } \\
\text { Not married }\end{array}$ & $\begin{array}{r}10.2(8.0-12.5) \\
17.3(14.3-20.3)\end{array}$ & $\begin{array}{c}\text { Ref } \\
1.8(1.2-2.5)\end{array}$ & $\begin{array}{c}\mathrm{NA}^{+\dagger} \\
8.3(5.6-10.9)\end{array}$ & $\begin{array}{c}\text { Ref } \\
2.5(1.1-6.0)\end{array}$ \\
\hline $\begin{array}{l}\text { Has a usual health care prov } \\
\text { Yes } \\
\text { No }\end{array}$ & $\begin{array}{l}11.9(10.1-13.7) \\
17.8(13.2-22.4)\end{array}$ & $\begin{array}{c}\text { Ref } \\
1.7(1.2-2.3)\end{array}$ & $\begin{array}{c}4.4(3.0-5.9) \\
7.2(3.2-11.3)^{* *}\end{array}$ & $\begin{array}{c}\text { Ref } \\
1.7(0.8-3.3)\end{array}$ \\
\hline $\begin{array}{l}\text { Frequent mental distress }{ }^{\S \S} \\
\text { Yes } \\
\text { No }\end{array}$ & $\begin{array}{r}27.4(19.7-35.0) \\
11.6(9.8-13.3)\end{array}$ & $\begin{array}{c}2.3(1.7-3.1) \\
\text { Ref }\end{array}$ & $\begin{array}{c}15.3(7.8-22.8)^{* * *} \\
3.8(2.4-5.1)\end{array}$ & $\begin{array}{c}3.4(1.9-5.8) \\
\text { Ref }\end{array}$ \\
\hline
\end{tabular}

Abbreviations: $\mathrm{aPR}=$ adjusted prevalence ratio; $\mathrm{NA}=$ not available; Ref $=$ referent group.

* Percentages weighted to represent national estimates of the U.S. population.

† Defined as consuming at least one alcoholic drink in the past 30 days.

$\S$ Defined as consuming four or more alcoholic drinks on one occasion at least once in the past 30 days.

" Model includes age, race/ethnicity, education, employment status, marital status, usual health care provider, and frequent mental distress.

** Estimate might be unstable because the relative SE is 0.2-0.3.

t+ Estimate suppressed because the relative $\mathrm{SE}$ is $>0.3$.

$\S \S$ Defined as reporting $\geq 14$ days of poor mental health in the past 30 days.

not differ significantly by year: $3.8 \%(2.4 \%-5.2 \%)$ in 2018 , $5.8 \%(3.2 \%-8.4 \%)$ in 2019 , and $6.1 \%(2.4 \%-9.7 \%)$ in $2020(\mathrm{p}=0.38)$. Current drinking differed by age, education, employment, and marital status, and binge drinking differed by employment and marital status. Pregnant adults reporting frequent mental distress had approximately twice the prevalence of current drinking $(\mathrm{aPR}=2.3[1.7-3.1])$ and approximately three times the prevalence of binge drinking $(\mathrm{aPR}=3.4$ [1.9-5.8]) as did those not reporting frequent mental distress. Pregnant adults without a usual health care provider more frequently reported current drinking $(17.8 \%$; aPR $=1.7$ [1.2-2.3]) than did those with a usual provider (11.9\%). Current drinking varied somewhat by HHS Regions (Figure), although differences were not statistically significant $(\mathrm{p}=0.25){ }^{\dagger \dagger \dagger}$

\section{Discussion}

During 2018-2020, approximately one in seven pregnant adults reported drinking alcohol in the past 30 days and, among those, approximately $40 \%$ reported binge drinking. Current and binge drinking increased by approximately 2 percentage points in 2018-2020 estimates compared with estimates from the previous 3-year period, consistent with an upward trend observed since $2011(2,4)$. There was no evidence of increased alcohol consumption by pregnant adults in 2020 relative to 2019, despite possible increased alcohol sales and consumption among the general population during the first months of the COVID-19 pandemic (5). $\$ \$ \$$

\footnotetext{
††† Region 1: Connecticut, Maine, Massachusetts, New Hampshire, Rhode Island, and Vermont; Region 2: New Jersey and New York; Region 3: Delaware, District of Columbia, Maryland, Pennsylvania, Virginia, and West Virginia; Region 4: Alabama, Florida, Georgia, Kentucky, Mississippi, North Carolina, South Carolina, and Tennessee; Region 5: Illinois, Indiana, Michigan, Minnesota, Ohio, and Wisconsin; Region 6: Arkansas, Louisiana, New Mexico, Oklahoma, and Texas; Region 7: Iowa, Kansas, Missouri, and Nebraska; Region 8: Colorado, Montana, North Dakota, South Dakota, Utah, and Wyoming; Region 9: Arizona, California, Hawaii, and Nevada; Region 10: Alaska, Idaho, Oregon, and Washington.

$\$ \$ \$$ https://pubs.niaaa.nih.gov/publications/surveillance-covid-19/COVSALES.htm
} 
FIGURE. Estimated prevalence* of current drinking ${ }^{\dagger}$ among pregnant adults aged 18-49 years ( $N=6,327$ ), by U.S. Department of Health and Human Services regions $s^{\S}$ - Behavioral Risk Factor Surveillance System, United States, 2018-2020

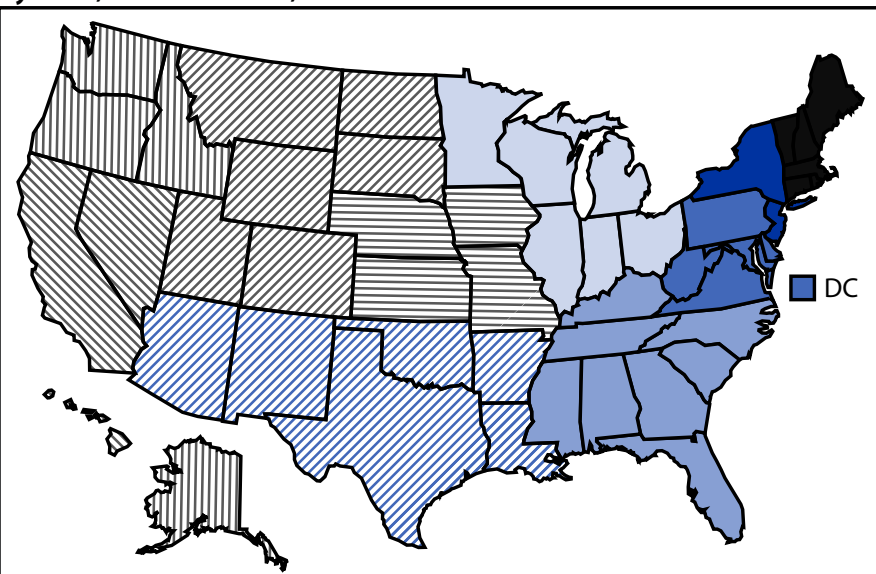

Region 1: 16.4\% (11.8\%-21.1\%) Region 2: $16.3 \%(12.1 \%-20.5 \%)$ Region 3: $11.6 \%(7.6 \%-15.6 \%)$ Region 4: $10.8 \%(7.7 \%-13.9 \%)$ Region 5: 15.4\% (11.3\%-19.4\%)

$\square$ Region 6: $11.2 \%(6.0 \%-16.5 \%)$ 目Region 7: $11.5 \%(7.5 \%-15.5 \%)$ Zegion 8: 10.8\% (11.8\%-14.3\%)

$\mathbb{N}$ Region 9: $16.7 \%(9.5 \%-23.9 \%)$

III Region 10: 13.2\% (9.5\%-17.0\%)

Abbreviation: DC = District of Columbia.

* Percentages weighted to represent national estimates of the U.S. population. Estimates for Region 9 and Region 6 might be unstable because the relative SEs are 0.2-0.3.

† Defined as having consumed at least one alcoholic drink in the past 30 days.

$\S$ Region 1: Connecticut, Maine, Massachusetts, New Hampshire, Rhode Island, and Vermont; Region 2: New Jersey and New York; Region 3: Delaware, District of Columbia, Maryland, Pennsylvania, Virginia, and West Virginia; Region 4: Alabama, Florida, Georgia, Kentucky, Mississippi, North Carolina, South Carolina, and Tennessee; Region 5: Illinois, Indiana, Michigan, Minnesota, Ohio, and Wisconsin; Region 6: Arkansas, Louisiana, New Mexico, Oklahoma, and Texas; Region 7: lowa, Kansas, Missouri, and Nebraska; Region 8: Colorado, Montana, North Dakota, South Dakota, Utah, and Wyoming; Region 9: Arizona, California, Hawaii, and Nevada; Region 10: Alaska, Idaho, Oregon, and Washington.

This report found several factors correlated with drinking during pregnancy including age, education, and marital status, which are generally consistent with other nationally representative studies $(4,6)$. Having a usual health care provider was associated with lower alcohol consumption. Having a usual health care provider might increase receipt of prevention services including alcohol screening and brief intervention, an effective tool universally recommended in primary care settings $(7,8)$. CDC is working to increase alcohol screening and brief intervention and community-level interventions. 999 Addressing barriers to having a usual health care provider might also help address alcohol consumption during pregnancy.

Frequent mental distress was correlated with current and binge drinking, although the direction of the relationship is unclear (9). Universal screening for anxiety and depression along with perinatal depression prevention interventions are

\footnotetext{
999 https://www.cdc.gov/ncbddd/fasd/alcohol-screening.html; https://www. thecommunityguide.org/topic/excessive-alcohol-consumption
}

\section{Summary}

What is already known about this topic?

Alcohol consumption during pregnancy can cause fetal alcohol spectrum disorders and might increase the risk for poor pregnancy and birth outcomes. There is no known safe amount of alcohol consumption during pregnancy.

What is added by this report?

During $2018-2020,13.5 \%$ of pregnant adults in the United States reported current drinking, and $5.2 \%$ reported binge drinking in the past 30 days. Those with no usual health care provider and those reporting frequent mental distress were more likely to consume alcohol.

What are the implications for public health practice?

High prevalence of alcohol consumption among pregnant adults requires integrated, evidence-based interventions to prevent alcohol-related harms and address factors associated with alcohol consumption.

recommended for women and pregnant adults.**** Integration of mental health services has been proposed in primary care setting and might be considered when addressing alcohol consumption during pregnancy (3).

The findings in this report are subject to at least five limitations. First, cross-sectional data limit inferences about temporal relationships. Second, low response rates could introduce selection bias. Third, data are self-reported and subject to misclassification related to recall and social desirability biases. Fourth, pregnancy might be misclassified because early pregnancies might be unrecognized. Finally, drinking was reported over a 30-day period which might not reflect drinking patterns earlier in pregnancy when consumption tends to be higher (10). These last three limitations might contribute to underestimates of drinking during pregnancy.

Alcohol consumption during pregnancy continues to be a serious problem. Addressing it requires clinical and community-wide interventions, such as alcohol screening and brief intervention and limiting alcohol sales. Improved access to care, including mental health services, might reduce prenatal alcohol use and prevent poor pregnancy and birth outcomes.

**** The Well-Woman Chart outlines preventive services recommended by the Women's Preventive Service Initiative, U.S. Preventive Services Task Force, and Bright Futures. https://www.womenspreventivehealth.org/wp-content/ uploads/WPSI_WWC_11x17_2021Update.pdf

\section{Acknowledgments}

Behavioral Risk Factor Surveillance System state coordinators. Corresponding author: Lucas K. Gosdin, nwj4@cdc.gov, 404-498-3347.

\footnotetext{
${ }^{1}$ Division of Birth Defects and Infant Disorders, National Center on Birth Defects and Developmental Disabilities, CDC; ${ }^{2}$ Epidemic Intelligence Service, CDC.
} 
All authors have completed and submitted the International Committee of Medical Journal Editors form for disclosure of potential conflicts of interest. No potential conflicts of interest were disclosed.

\section{References}

1. Bailey BA, Sokol RJ. Prenatal alcohol exposure and miscarriage, stillbirth, preterm delivery, and sudden infant death syndrome. Alcohol Res Health 2011;34:86-91. PMID:23580045

2. Denny CH, Acero CS, Terplan M, Kim SY. Trends in alcohol use among pregnant women in the U.S., 2011-2018. Am J Prev Med 2020;59:768-9. PMID:33011009 https://doi.org/10.1016/j.amepre.2020.05.017

3. National Council for Mental Wellbeing. Substance use disorders and the person-centered healthcare home. Washington, DC; 2010. https://www. thenationalcouncil.org/wp-content/uploads/2020/01/National_Council_ SU_Report.pdf?daf $=375$ ateTbd 56

4. Denny CH, Acero CS, Naimi TS, Kim SY. Consumption of alcohol beverages and binge drinking among pregnant women aged 18-44 yearsUnited States, 2015-2017. MMWR Morb Mortal Wkly Rep 2019;68:365-8. PMID:31022164 https://doi.org/10.15585/mmwr.mm6816a1

5. Barbosa C, Cowell AJ, Dowd WN. Alcohol consumption in response to the COVID-19 pandemic in the United States. J Addict Med 2021;15:341-4. PMID:33105169 https://doi.org/10.1097/ ADM.0000000000000767
6. Grant BF, Chou SP, Saha TD, et al. Prevalence of 12-month alcohol use, high-risk drinking, and DSM-IV alcohol use disorder in the United States, 2001-2002 to 2012-2013: Results from the National Epidemiologic Survey on Alcohol and Related Conditions. JAMA Psychiatry 2017;74:911-23. PMID:28793133 https://doi.org/10.1001/ jamapsychiatry.2017.2161

7. Curry SJ, Krist AH, Owens DK, et al.; US Preventive Services Task Force. Screening and behavioral counseling interventions to reduce unhealthy alcohol use in adolescents and adults: US Preventive Services Task Force recommendation statement. JAMA 2018;320:1899-909. PMID:30422199 https://doi.org/10.1001/jama.2018.16789

8. American College of Obstetricians and Gynecologists. American College of Obstetricians and Gynecologists committee opinion no. 762: Prepregnancy counseling. Obstet Gynecol 2019;133:e78-89. PMID: 30575679 https://doi.org/10.1097/AOG.0000000000003013

9. McHugh RK, Weiss RD. Alcohol use disorder and depressive disorders. Alcohol Res 2019;40:arcr.v40.1.01. PMID:31649834 https://doi. org/10.35946/arcr.v40.1.01

10. Ethen MK, Ramadhani TA, Scheuerle AE, et al.; National Birth Defects Prevention Study. Alcohol consumption by women before and during pregnancy. Matern Child Health J 2009;13:274-85. PMID:18317893 https://doi.org/10.1007/s10995-008-0328-2 